\title{
MERCADO LINGUÍSTICO FAMILIAR: GERENCIAMENTO DE LÍNGUAS EM UMA FAMÍLIA SUL-COREANA ${ }^{1}$
}

\section{FAMILY LANGUAGE MARKET: LANGUAGE MANAGEMENT IN A SOUTH KOREAN FAMILY}

\author{
Tatiana Martins Gabas ${ }^{2}$
}

\begin{abstract}
RESUMO Este artigo tem como objetivo discutir o gerenciamento linguístico empreendido por uma mãe da comunidade sul-coreana de trabalhadores transplantados residente na Região Metropolitana de Campinas (RMC), a partir de suas representações acerca das línguas que compõem o repertório linguístico dos membros de sua família (coreano, português e inglês). $O$ instrumento adotado para a geração de dados foi entrevista semiestruturada, gravada em áudio digital. O principal referencial teórico utilizado incluiu considerações acerca da noção de domínios e de gerenciamento linguístico (SPOLSKY, 2007; 2009), bem como das implicações de Políticas Linguísticas Familiares em Contextos Plurilíngues (KING; FOGLE; LOGAN-TERRY, 2008; SPOLSKY, 2012; FOGLE; KING, 2013, entre outros). A análise dos dados demonstrou que o valor atribuído pela mãegerenciadora às línguas do repertório da família tem impacto direto no gerenciamento linguístico em andamento. $O$ trabalho buscou oferecer um panorama de como o domínio familiar pode ser pertinente para compreensão de como línguas são gerenciadas em contexto de mobilidade transnacional.
\end{abstract}

PALAVRAS-CHAVE: política linguística familiar; gerenciamento linguístico; migração transnacional sul-coreana.

\begin{abstract}
The aim of this article is to reflect upon ongoing language management held by a mother from a community of South Korean transplanted workers located in Campinas Metropolitan Area, based on her representations about the languages that are part of the linguistic repertoire of her family members (Korean, Portuguese and English). The data was generated throughout individual semi-structured interviews, recorded in digital audio. The main theory which supports this investigation included reflections about the concepts of domain and language management (SPOLSKY, 2007; 2009), as well as the implications of Family Language Policy in multilingual settings (KING; FOGLE; LOGAN-TERRY, 2008; SPOLSKY, 2012; FOGLE; KING, 2013, among others). Data analysis demonstrated that the value assigned by the manager-mother for the languages that are part of the family linguistic

\footnotetext{
${ }^{1}$ Esse artigo deriva da Dissertação de Mestrado desenvolvida pelo autor.

${ }^{2}$ Mestra em Linguística Aplicada pela UNICAMP. Professora de Português como Língua Adicional para a comunidade sulcoreana de Campinas.
} 
repertoire has central impact on the ongoing language management. The article intended to offer an overview of how the family domain can be relevant to understand the way languages are managed in contexts of transnational mobility.

KEYWORDS: family language policy; language management; South Korean transnational migration.

\section{Introdução}

Com a retomada do fluxo da imigração para o Brasil no final do século XX, o Brasil novamente entrou na rota das migrações internacionais propiciando a entrada de novos contingentes de imigrantes (BAERNINGER, 2003). Em decorrência disso, a partir da década de 1980, a instalação de empresas sul-coreanas transnacionais no Brasil, mais especificamente na Região Metropolitana de Campinas (RMC), resultou na formação de uma comunidade de trabalhadores transplantados, nos termos de Amado (2011), composta por funcionários e seus familiares. Em sua maioria, esses trabalhadores visualizam na mudança para o Brasil uma possibilidade de crescimento profissional para si e pessoal para seus familiares, e percebem a sua permanência temporária no país também como uma oportunidade para a ampliação do repertório linguístico, principalmente o de seus filhos. As práticas linguísticas desses membros não ocorrem em apenas uma língua isoladamente e as famílias, principalmente as mães, se veem instadas a tomar decisões acerca das línguas que compõem seus repertórios e o de seus filhos: coreano, inglês e português. ${ }^{3}$

Em virtude disso, proponho-me a discutir algumas representações dessas línguas presentes no discurso de uma mãe pertencente a esta comunidade sul-coreana de trabalhadores transplantados, de modo a ilustrar e refletir como essas representações sinalizam o gerenciamento linguístico por ela empreendido, isto é, Políticas Linguísticas Familiares em andamento no domínio familiar.

Para tanto, a noção de representação, tal como entendida por Hall (1997), me acompanhou durante a análise dos dados gerados por meio de entrevista semiestruturada ${ }^{4}$. Na esteira do que propõe o autor, representações são processos de produção de sentido

\footnotetext{
${ }^{3}$ Ao longo do texto, embora me refira, por uma questão de praticidade, às línguas do repertório como "coreano", "inglês" e "português", coerentemente com a afiliação teórica que adoto, não considero que essas línguas sejam aqui entendidas como entidades discretas e compartimentalizadas e que seus falantes dela se utilizem isoladamente.

${ }^{4}$ O projeto de pesquisa inicial passou por avaliação do CEP (Comitê de Ética em Pesquisa), tendo sido aprovado.
} 
socialmente construídos, historicamente situados, continuamente reinventados, e, por isso, transitórios.

Divido o artigo em seis partes. Na primeira, discorro sobre plurilinguismo e transnacionalismo, fenômeno este que desencadeou o estabelecimento da comunidade em questão, e, em seguida, descrevo a comunidade sul-coreana. Na terceira seção, discuto a noção de domínios e gerenciamento linguístico, bem como o campo de estudos sobre Política Linguística Familiar. Posteriormente, nas seções quatro e cinco, discorro sobre a organização familiar sul-coreana e sobre o processo de geração de dados. Por fim, apresento a análise de dados.

\section{Deslocamentos Transnacionais e Plurilinguismo}

Antes de iniciar uma descrição breve da comunidade aqui abordada, é importante pontuar algumas questões acerca da íntima relação entre transnacionalismo e plurilinguismo, para melhor compreensão das dinâmicas que caracterizam o tipo de imigração aqui descrito.

$\mathrm{O}$ transnacionalismo, ou seja, as novas alianças internacionais que reconfiguraram as relações entre países, resulta no trânsito crescente de pessoas em fluxo e impulsiona a formação de comunidades cada vez mais plurilíngues. Dessa forma, o plurilinguismo, antes uma realidade pouco reconhecida, quando não negada, está hoje cada vez mais notório em diversas partes do planeta e também presente na agenda das pesquisas contemporâneas (HORNBERGER, 2006; SHOHAMY, 2006; HELLER, 2003; CANAGARAJAH, 2013; MAHER, 2013).

A exemplo da comunidade sul-coreana presente na RMC, há, atualmente, nos grandes centros urbanos, a presença de pessoas com múltiplas trajetórias que carregam consigo repertórios e padrões de usos linguísticos específicos (MARTIN-JONES; BLACKLEDGE; CREESE, 2012). Com múltiplas trajetórias, os sujeitos transnacionais não se encaixam mais no modelo linear de aquisição linguística - língua de origem/língua do país de destino - tendo seus repertórios linguísticos ampliados de forma significativa. Como explica Shohamy (2006), os sujeitos transnacionais possuem uma forma complexa de uso e gerenciamento de línguas que passam a compor seus repertórios, possibilitando novas formas de pertencimento e afiliação ${ }^{5}$.

\footnotetext{
5 Na esteira do que discutem Heller (2003), Jacquemet (2005) e Reyes (2014), no contexto dos deslocamentos contemporâneos, as experiências de mobilidade, bem como as experiências linguísticas, principalmente no que se refere ao acesso aos recursos linguísticos e culturais, ocorrem de forma não-linear e estão subordinadas às trajetórias dos sujeitos, uma vez que há restrições ao trânsito de certas nacionalidades e de certos grupos sociais, bem como de suas línguas.
} 
Vai daí, como insistem vários autores (BUSH, 2012; CANAGARAJAH, 2013; RYMES, 2014), com os quais este trabalho está alinhado, a importância de se considerar o repertório linguístico dos falantes como um todo e não cada uma de suas línguas individualmente. Estes autores entendem que as línguas devem ser concebidas como entidades móveis, que interagem entre si e compõem o repertório de um falante, falante este que situacionalmente as utiliza como recursos altamente produtivos na interação. Assim, nesse cenário, concepções monolíticas de língua se tornam ainda mais improdutivas para o entendimento do plurilinguismo, porque destituem as línguas das pessoas, dos usos e dos contextos nos quais estão inseridas.

É a partir da noção de repertório linguístico que discorro sobre a comunidade em questão.

\section{A comunidade sul-coreana de trabalhadores transplantados da RMC}

A partir do fortalecimento das relações de comércio entre o Brasil e a Coreia do Sul, o segundo movimento de entrada de coreanos no Brasil ${ }^{6}$ teve início, no final da década 1980 , com a instalação de duas empresas sul-coreanas, a Samsung e a LG, na Região Metropolitana de Campinas (RMC), e ocasionou a transplantação de mão-de-obra qualificada para o interior do Estado de São Paulo.

Em meados da década de 2000, outra onda de investimentos trouxe à RMC e à Região Administrativa de Campinas mais empresas sul-coreanas do setor automotivo e de engenharia, entre elas a Hyundai ${ }^{7}$, fortalecendo a presença sul-coreana no cenário econômico brasileiro bem como ampliando o tamanho da comunidade na região. Segundo dados do SEADE (2014), as empresas sul-coreanas da RMC, ao lado de empresas japonesas e chinesas da Região Metropolitana de Sorocaba, compõem o chamado "corredor asiático" e figuram como o segundo maior polo industrial do país, sendo responsável por 1/3 do PIB do Estado de SP..$^{8}$

A comunidade sul-coreana pode ser descrita como um tipo de comunidade específica, devido ao caráter temporário de estadia de seus membros acompanhados de suas famílias. As empresas recebem um fluxo de funcionários em esquema rotativo, porém contínuo, que se

\footnotetext{
${ }^{6}$ A primeira imigração sul-coreana para o Brasil, distinta dessa em questão, foi iniciada em 1963 com a vinda de refugiados da Guerra da Coreia (1950-1953). Para um panorama dessa imigração, consultar o trabalho de Choi (1991) e (1996).

7 A instalação da Hyundai atraiu a vinda de outras 26 empresas sul-coreanas. Informação disponível em: http://economia.estadao.com.br/noticias/geral,coreanos-iniciam-segunda-onda-de-investimentos-imp-,679294. Acesso em 02 jan.2016.

${ }^{8}$ Disponível em: https://www.seade.gov.br/wp-content/uploads/2014/06/Primeira_Analise_n1_abril_2013.pdf Acessado em 20 mai. 2016.
} 
deslocam para suprir a alta demanda de mão-de-obra de alta capacitação desses locais. Em alguns casos, são trabalhadores com experiências anteriores de transplantação para outros países. ${ }^{9}$ Embora a comunidade possua uma dinâmica diferente, em função da mobilidade, tem suas práticas sociais e linguísticas igualmente compartilhadas e co-construídas socialmente em domínios como a escola, a empresa, o clube de lazer, a igreja e a família, sendo este último o domínio aqui focalizado.

O aspecto educacional, com bastante peso nas dinâmicas familiares dessa comunidade, se deve ao reconhecido envolvimento das famílias sul-coreanas na vida escolar dos filhos. Assim, embora as empresas estejam instaladas em diversas cidades da RMC e da RAC ${ }^{10}$, as famílias da comunidade residem majoritariamente no município de Campinas, devido à oferta de mais opções educacionais, como escolas bilíngues e internacionais, sendo as internacionais as opções preferidas pela família. A preferência por essas escolas se dá em virtude da língua de instrução principal ser o inglês (LI). ${ }^{11}$

Fatores como o tempo de residência no Brasil, experiências anteriores de transplantação, o retorno para a Coreia do Sul e/ou o deslocamento posterior para outro país exige um gerenciamento de línguas bastante específico por parte das mães que são responsáveis linguisticamente por seus filhos e por suas trajetórias linguísticas que são marcadas por deslocamentos transnacionais.

\section{Gerenciamento Linguístico e Política Linguística Familiar}

As decisões tomadas por uma mãe sul-coreana acerca das línguas do repertório de seus filhos sinalizam as Políticas Linguísticas Familiares (PLF) sendo estabelecidas neste domínio. O campo de estudos em PLF emergiu da Política Linguística e deriva da perspectiva de língua-como-recurso, principalmente no que se refere à potência de PLs não-oficiais, de orientação bottom-up que, em diálogo com PLs oficiais, estão longe de serem homogêneas.

A PLF, enquanto campo de estudos, tradicionalmente se voltou para práticas de famílias bi ou multilíngues, objetivando a compreensão acerca das ações explícitas ou implícitas de um membro familiar, que a partir de sua autoridade, decide intervir sobre a(s)

\footnotetext{
${ }^{9}$ Empresas como Hyundai e Samsung possuem filiais em diversos países como Estados Unidos, Índia, Turquia, México, China, Vietnã e Rússia.

${ }^{10}$ Além de cidades como Campinas e Piracicaba, há empresas instaladas em Americana, Limeira, São Pedro, Sumaré, entre outras.

${ }^{11}$ A língua portuguesa (LP) geralmente compõe uma parte minoritária no currículo. Ainda assim, o fortalecimento e o aprendizado dessas duas línguas ocorrem geralmente em casa, com aulas particulares, onde também ocorre a manutenção da língua coreana por meio de rotinas de estudo organizadas pelas mães.
} 
língua(s) de outro(s) membro(s) da família possibilitando compreender como como essa(s) língua(s) são valoradas, utilizadas e gerenciadas localmente (KING; FOGLE e LOGANTERRY, 2008; SPOLSKY, 2012; FOGLE; KING; LOGAN-TERRY, 2013; KAYAM; HIRSCH, 2013). ${ }^{12}$

No trabalho, tomo a noção de família enquanto domínio conforme discutido por Spolsky (2004; 2007; 2009; 2012), isto é, noção como espaços sociais compostos por participantes que são caracterizados por seus papeis sociais e pela relação que estabelecem com outros membros do domínio, relações essas orientadas pelo entendimento das regras compartilhadas por todos os membros. A partir da noção de domínio, Spolsky define a noção de gerenciamento linguístico ${ }^{13}$, ou seja, esforços explícitos e estratégias que visam alterar práticas e crenças sobre uma língua, empreendidos por membros de um domínio orientados por crenças e ideologias atribuídos às línguas que compõem os repertórios linguísticos.

O gerenciamento linguístico empreendido pelos membros de uma família envolve a utilização de estratégias para a manutenção, adoção ou apagamento de línguas do repertório da família. O controle do ambiente linguístico, entre outros, é um mecanismo de gerenciamento de línguas recorrentemente utilizado pelos pais ou outros gerenciadores, e bastante produtivo na intervenção sobre o repertório dos membros da família, quer seja por casais interétnicos ou endógamos (SPOLSKY, 2009).

Importa ressaltar que os papeis dos diferentes membros de uma família variam a partir das relações de poder que estão constantemente sendo disputadas ou negociadas repercutindo na maneira como gerenciamentos são realizados. A figura do gerenciador depende dos padrões culturais da sociedade em que a família está inserida e também é uma posição conquistada e alcançada por meio da autoridade (SPOLSKY, 2009): quanto maior a autoridade maior o gerenciamento. Além disso, o núcleo familiar por ser poroso e por estar aberto a múltiplas influências (CANAGARAJAH, 2008) está atravessado por diferentes ideologias linguísticas. Assim, a organização familiar e outros componentes extralinguísticos têm muita relevância para o modo como os gerenciadores, a partir de suas posições de autoridade, desempenham papeis de gerenciamento.

As ideologias linguísticas, ou seja, os valores e status atribuídos às variedades, estilos e línguas que compõem os repertórios linguísticos dos falantes têm papel relevante no gerenciamento de Políticas Linguísticas no domínio familiar (SPOLSKY, 2012). Isso porque

\footnotetext{
${ }^{12}$ Embora se constituam em um campo específico de estudos, as produções acadêmicas na área de Políticas Linguísticas Familiares são ainda escassas, principalmente no Brasil. Destaco os trabalhos de Coelho (2009) e Moroni (2012; 2015).

${ }^{13} \mathrm{O}$ autor divide gerenciamento linguístico entre simples, quando uma pessoa toma decisões para si, e organizado, quando realiza intervenções na língua de outro membro.
} 
o conjunto de crenças que as pessoas têm acerca desses repertórios influencia a maneira como acreditam que devam ser o aprendizado ou o fortalecimento de línguas em todos os domínios sociais (HELLER, 2007; MOITA LOPES, 2013).

No contexto sul-coreano, há um grau alto de engajamento dos pais no controle das decisões linguísticas que envolvem seus filhos (PARK; ABELMANN, 2004; KIM, 2009; LEE, 2010; PARK, LIM; CHOI, 2015) conforme exploro abaixo.

\section{Organização familiar sul-coreana e ideologias linguísticas na Coreia do Sul}

A estrutura familiar coreana, conforme Kim (2002) e Cho (2005) é uma organização centrada na figura dos filhos em oposição à organização centrada nos cônjuges. Nesse contexto, todos os esforços familiares se concentram no planejamento futuro em termos de conquistar boas oportunidades educacionais para os filhos. Essa função é desempenhada primordialmente pela mãe que, com o sucesso acadêmico dos filhos, tem seu sacrifício condecorado lhes garantindo prestígio (LEE, 2010). Há dois exemplos de modelos maternos muito recorrentes que denotam o envolvimento máximo das mães sul-coreanas em estratégias de gerenciamento educacional e linguístico as mãe de Gangnam $^{14}$ (PARK; LIM; CHOI, 2015) e as mães kirogi ${ }^{15}$ (KIM, 2009; LEE, 2010).

Em uma sociedade com altos índices de pessoas com diploma de Ensino Superior ${ }^{16}$, o sucesso acadêmico é chave integral para a manutenção ou ascendência social da família e o engajamento profundo em todos os aspectos da esfera educacional da vida dos filhos tende a condicionar o convívio das mães às redes de contatos que fortaleçam suas estratégias de gerenciamento educacional, além dos gerenciamentos doméstico e financeiro. A busca pelas melhores estratégias para o sucesso dos filhos objetiva o alto desempenho dos filhos no Suneung, o exame nacional unificado, que seleciona os candidatos para as universidades públicas e privadas. Principalmente no desempenho nas três disciplinas mais importantes do teste: língua coreana, matemática e língua inglesa.

Dessa forma, a função de gerenciadora da mãe é ainda mais fundamental no período de transplantação da família, pois além da adição de outras línguas ao repertório dos filhos e

\footnotetext{
${ }^{14} \mathrm{O}$ nome faz referência à presença recorrente de mães nos cafés e restaurantes de Gangam, distrito de alto padrão de Seoul, conhecidas por se engajarem vigorosamente e de forma dinâmica na busca por informações educacionais valiosas que contribuirão para o sucesso acadêmico dos filhos.

${ }^{15}$ Kirogi significa "ganso selvagem" em coreano e caracteriza mães que que migram para países de língua inglesa com os filhos, deixando o marido na Coreia do Sul, visando fortalecer a proficiência dos filhos nessa língua de prestígio.

16 Dados apresentados no relatório de Indicadores Educacionais da 2014 da OECD (Organização para Cooperação e Desenvolvimento Econômico). Disponível em: http://www.oecd.org/edu/Korea-EAG2014-Country-Note.pdf. Acesso em: 20 jan. 2016.
} 
da família, a mãe-gerenciadora precisa igualmente administrar a adaptação à escola no Brasil, bem como planejar a readaptação em outra escola no futuro, quer seja na Coreia do Sul ou em outro país. E é esse gerenciamento que procurei focalizar na seção de análise. Antes descrevo brevemente o processo de geração de dados.

\section{Geração de dados}

O principal instrumento adotado para a geração de dados foi a entrevista semiestruturada roteirizada por perguntas ou tópicos previamente elaborados, que orientaram a sua condução (FLICK, 2009). ${ }^{17}$ As perguntas foram traçadas, a partir do histórico familiar já conhecido da interlocutora e das reflexões suscitadas durante aulas de português ou conversas informais ocorridas anteriormente à entrevista ${ }^{18}$.

A entrevista foi realizada na casa da participante, sem a presença dos filhos, gravada em áudio digital com tempo aproximado de 50 minutos e posteriormente roteirizada, sendo os trechos mais relevantes transcritos a partir das seguintes convenções:

\begin{tabular}{|c|c|}
\hline \multicolumn{2}{|c|}{ CONVENÇÕES UTILIZADAS NAS } \\
TRANSCRIÇÕES DOS REGISTROS \\
\hline$\ldots$ & pausa de mais de 02 \\
segundos
\end{tabular}

\footnotetext{
${ }^{17}$ Foram igualmente utilizadas de forma complementar anotações registradas em diário de campo retrospectivo.

${ }^{18}$ A participante em questão foi minha aluna de português particular durante aproximadamente 3 anos. Em parte desse período também tive a oportunidade de ensinar português para seu filho mais velho.
} 


\section{O gerenciamento de Yoona: relatos de uma mãe-sul coreana}

Em decorrência da transferência do marido, a família de Yoona ${ }^{19}$ se mudou para o Brasil em 2011 e aqui permaneceu durante quatro anos e meio. À época da geração de dados, seus dois filhos tinham 9 e 6 anos e retornariam para a Coreia após seis meses. Durante o período de residência no Brasil, assim como muitas mães da comunidade, Yoona esteve no controle do gerenciamento educacional e linguístico dos filhos.

Apresento dessa forma, as representações que mãe-gerenciadora faz das línguas usadas nas práticas comunicativas da família:

T.: E que língua vocês falam na sua casa, Yoona?

Y.: Coreano e português.

T.: Na sua casa?

Y.: Sim. Em primeiro coreano e segundo português. Porque meus filhos se conversam em português, então eu também às vezes usa, fala, falo português, sim, mas quando meu marido chega, ele não sabe falar português, nós falamos $((\text { riso nervoso }))^{20}$ em coreano, sim.

O trecho é ilustrativo de que as práticas linguísticas dos membros da família de Yoona em casa ocorrem em mais de uma língua, português e coreano, mas o modo como ela lista a utilização dessas línguas - "em primeiro coreano e segundo português" - sugere que essa mãe julgue mais adequado que o uso da língua coreana seja predominante nos lares de famílias transplantadas. Soma-se a essa condição o riso nervoso de Yoona, um riso muito característico que atravessa diferentes práticas linguísticas asiáticas, e em especial as sulcoreanas. É um tipo de riso que demonstra desconforto e pode ser assinalado a partir da posição em que ocorre na fala, que é muito recorrente no meio da sentença. Esse tipo de riso sugere um desconforto pelo fato de a língua coreana não ser a única a fazer parte do ambiente linguístico familiar, tampouco ser às vezes a de preferência.

O português tem lugar nas práticas comunicativas da família muito em função dos investimentos que realizou para o aprendizado do português ${ }^{21}$. Para ela, investir no

\footnotetext{
19 Ressalto que seu nome foi substituído de modo a preservar sua identidade, assim como foram alteradas algumas informações sobre sua família.

${ }^{20}$ A partir das anotações de diário de campo, infiro que ao rir dessa forma a participante geralmente olhava para baixo ou fechava os olhos, além disso, esse riso é mais contido do que um riso que expresse humor.

${ }^{21}$ Um exemplo do grau desse investimento é o fato de que no penúltimo ano de residência no Brasil, Yoona obteve certificação no exame Celpe-Bras.
} 
aprendizado do português foi a chave para uma melhor adaptação no país. Ela define o seu próprio aprendizado da língua como:

Desvantagem ((de vir morar no Brasil)) é por causa da língua, acho que é DIFÍCIL, no início é difícil ir ao médico, éh... quando meus filhos estavam doente, estava muito difícil, mas agora, éh..., melhorou. (...) eu aprendi português, né? ((risos)) Então, quando eu quer ir ao médico, eu POsso ir. E meus filhos também. Meus filhos sabem falar português muito bem, então eles também fazem amizade com brasileiro, já acostumou escola brasileiro, sim, acho que agora, acho que não tem mais problema.

O investimento na língua portuguesa é um indício forte do status positivo que atribui ao português e sua representação tem impacto direto no modo como gerencia o fortalecimento dessa língua para os filhos. O gerenciamento linguístico que faz para si, ou gerenciamento simples como define Spolsky (2009), orientou o gerenciamento que fez para os filhos, conforme descreve em outro trecho da entrevista:

Quando chegou, para eles acostumar com Brasil, eh...é mais importante estudar português, né? Então eles ((os filhos)) estudava português mais, ((língua)) coreana acho que eu não ensinei aquele momento, mas hoje em dia precisa estudar coreano mais.

Nesse relato, são narradas as decisões que tomou em diferentes estágios do período de transplantação, optando, inicialmente, por investir mais no português ("para eles acostumar com Brasil, eh..., é mais importante estudar português, né?”) e, no último ano, se voltando para o investimento na língua coreana com vistas ao retorno ao seu país de origem. Essas decisões são informadas por ideologias linguísticas e, à luz de Woolard (1998), são ideologias intimamente imbricadas com os aspectos político e sociais e apontam para o contexto em que essas ideias estão em circulação. Assim, as diferentes decisões que Yoona vai tomando durante toda a transplantação, ora com mais investimento em uma língua, ora com mais investimento em outra, evidencia que ela está orientada pelas ideologias do contexto do qual está mais próxima, daí investir mais na língua coreana no final do período de residência, porque entende que as ideias sobre as línguas em circulação naquele contexto são diferentes das que circulam no seu país.

A representação que faz das línguas do repertório dos filhos marca o gerenciamento que empreende, principalmente com vistas ao fortalecimento do coreano quando do retorno à Coreia do Sul: 
SEMpre no fim de semana, eu ensino coreano para eles...hum...sim. (...) Sempre elas ((as crianças)) estudam comigo. (...) Nós não temos muito tempo para voltar para Coreia, então meus filhos têm que estuda mais forte, mais intensivo, então é melhor eu ensino para elas.

É relevante observar o modo como essa mãe enfatiza a sua condição de gerenciadora direta desse fortalecimento e de instrutora da língua, o que é visível nos constantes "eu ensino" e no uso de "comigo". Yoona compreende que o retorno está próximo, e intensifica o ensino da língua coreana em casa, porque entende haver mais garantias do aumento de proficiência nessa língua se o seu ensino ficasse sob o seu controle ("então é melhor eu ensino").

Para isso ela adota estratégias bastante pontuais:

T.: E como você organiza isso, Yoona? Tem livro?

Y.: Sim tem livro, eu comprei lá na Coreia e eu trouxe e eu ensino. Sim, com livro eu sempre ensino.

E descreve a experiência de ser instrutora de LC para os filhos:

Y.: Eles não gostam... ((riso nervoso)) Eles não gosta, eu forço estudar coreano ((riso nervoso) $) \ldots$ eles não gos[tam.

T.: [Que que você acha disso?

Y.: Acho que pra eles é MAIS difícil estudar coreano (...) Eu tenho que explicar porque eles estudam coreano, SEMPRE eu explico...eles não querem voltar para a Coreia $(\ldots)$

Nota-se, nessas falas, que há resistência dos filhos em se engajar no aprendizado da LC, evidenciado pelos trechos "eles não gostam". A estrutura "eu forço estudar coreano" muito provavelmente têm eco da estrutura correlata em língua inglesa, I force them $t^{22}$, e oferece pistas de uma negociação em curso, em que a mãe não é soberana no papel de gerenciadora. Além disso, o trecho "SEMPRE eu explico" evidencia a ênfase da mãe para que as crianças se engajem no estudo do coreano por ela proposto. Ambos os trechos destacados mostram o papel agentivo das crianças (FOGLE E KING, 2013) que utilizam mecanismos para negociar e resistir às decisões tomadas pelos pais, a fim de poderem igualmente decidir sobre as línguas do domínio familiar.

A escolha das escolas onde os filhos de Yoona estudaram, conforme narrado por ela, é significativa do tipo de planejamento linguístico que traçou:

\footnotetext{
${ }^{22}$ Língua que é falada e que foi aprendida pela mãe anteriormente ao português.
} 
Elas estudavam na escola brasileira ((no início)), né? (...) então meus filhos estudavam aquele escola.

(...)

Depois meu filho mais velho mudou para a escola internacional, e agora meu filho mais novo vai na escola internacional ou brasileira, eu não sei, vai... aquela escola usa bilingual, inglês-português, então ele também começou a estudar inglês.

A escolha da (s) escola (s) a ser (em) frequentada (s) pelos filhos é uma estratégia importante de gerenciamento e um indício forte das políticas linguísticas estabelecidas pelas famílias. Spolsky (2009), apoiado em Harris (1996), aponta que os pais frequentemente investem em estratégias que garantem controle do ambiente linguístico externo porque, em algumas situações, isso é mais importante do que o ambiente doméstico para dar suporte às PLF sendo conduzidas.

A representação da língua inglesa reproduzida no discurso da mãe está em consonância com o prestígio altamente positivo dessa língua na Coreia do Sul (PARK; ABELMANN, 2004; PILLER; CHO, 2013) ${ }^{23}$, fato que orienta sua decisão:

Na Coreia, eh... primeiro língua estrangeira é inglês. Inglês é muito importante para entrar ((na universidade)) ... trabalhar na empresa, sempre precisa de inglês, de certificado de inglês. Inglês é muito importante naquele, na Coreia. Então eles TÊM que estudar inglês.

É interessante observar o modo como reproduz e marca essa ideologia ao dizer "TÊM que", ou seja, não é opcional. O inglês tem status garantido porque é "muito importante" e "sempre precisa de inglês". Valor este, que também e compartilhado por outros pais da comunidade:

Para crianças, ((outros)) pais também quer que filhos sabem falar inglês muito bem, primeiro língua é inglês, então, em primeiro, muitos pais deixam eles estudar só inglês, passa um tempo e depois, às vezes eles estudam português, mas acho que não é suficiente para falar ((risos)).

\footnotetext{
${ }^{23}$ O final da década de 1990 foi um período bastante significativo para a consolidação de Ideologias Econômicas, Educacionais e Linguísticas no país. A ideologia econômica do neoliberalismo serviu como um mecanismo de política linguística desencadeando a disseminação do inglês.
} 
Ao descrever a ordem de importância das línguas, Yoona revela forças internas e externas - de natureza não apenas linguística - que atuam no seio de sua família e de outras famílias da comunidade, - que contribuem para determinar a Políticas Linguísticas em andamento.

Ainda que se alinhe às ideologias de LI em circulação na Coreia do Sul, Yoona consegue ao mesmo tempo atribuir um sentido positivo à língua portuguesa:

(...) Então na Coreia também, ah...todo mundo quer falar inglês e chinês e outra língua também, então português é ainda não popular e famoso, mas acho que no FUTURO o português também fica mais popular e famoso, e éh, hum... é fácil aprender espanhol, né?, se eu fala português bem. Então acho que é imporTANte. Eh...e meu filho e eu tem interesse em português, então é muito divertido. Isso é muito importante né? ((risos)) muito divertida e... é bom.

Ela reconhece que o português tem baixo prestígio na Coreia do Sul. Ainda assim, ratifica seu interesse e o interesse do filho mais velho pela LP e toma decisões em favor dessa língua, atribuindo-lhe inclusive outras funções futuras (é fácil aprender espanhol, né?, se eu fala português bem). Além disso, o português é uma língua à qual ela e o filho estão emocionalmente ligados (então é muito divertido), língua que também é constitutiva de suas identidades, ainda que não goze do mesmo prestígio da LI.

\section{Considerações Finais}

O valor que Yoona atribui às línguas do repertório da família influencia o gerenciamento linguístico que empreende neste domínio. As decisões linguísticas que toma para os filhos estão intimamente ligadas ao gerenciamento que faz de seu próprio repertório linguístico, principalmente no que se refere ao gerenciamento do português. Como gerenciadora desse mercado linguístico familiar, Yoona administra as línguas do repertório de modo a estabelecer uma relação de cooperação entre o inglês, o coreano e o português.

A família transnacional é um exemplo significativo dos deslocamentos contemporâneos. Trata-se de um domínio muito pertinente para compreender como as línguas se articulam nas experiências de mobilidade, porque oferece um panorama de como Políticas Linguísticas, de escala top-down e bottom-up, se sobrepõem no trânsito/tensão entre "global" e "local". No artigo, busquei demonstrar que esse trânsito/tensão se manifesta principalmente 
nas decisões que a mãe-gerenciadora toma acerca do aprendizado do português. $\mathrm{Na}$ comunidade em questão e, por extensão, na Coreia do Sul, o inglês tem papel central no gerenciamento das mães, mas Yoona encontra uma possibilidade de inseri-lo no planejamento familiar. Mesmo que reproduza as ideologias linguísticas dominantes em favor da língua inglesa, em suas práticas e ações de gerenciamento linguístico ela cria lugares onde o português também possa ter espaço e ser motivo de aprendizado.

Há ainda muito para se compreender na área de Políticas Linguísticas Familiares, uma área de investigação ainda pouco explorada em nosso país, especialmente em contextos de migrações transnacionais. Espero que o estudo aqui apresentado possa ter contribuído para a área de Políticas Linguísticas, principalmente no que se refere à análise de representações e decisões acerca de línguas à luz do conceito de gerenciamento linguístico (SPOLSKY, 2009), um conceito bastante pertinente para discussão de Política Linguística de escala bottom-up.

Não perco de visto que os dados aqui apresentados fornecem indícios para compreender Políticas Linguísticas em andamento em uma família sul-coreana, ainda que tenha me detido na representação da mãe-gerenciadora apenas. Para uma compreensão mais heurística de como Políticas Linguísticas são estabelecidas no domínio familiar, é necessário também buscar compreensão acerca das representações de outros membros desse domínio, bem como de outros domínios que atravessam a família.

Vale lembrar que Políticas Linguísticas contexto de mobilidade também compõem o quadro de Políticas Linguísticas brasileiras e merecem ser objeto de estudos de cada vez mais pesquisas visando à compreensão do plurilinguismo.

\section{Referências}

AMADO, Roseane de Sá. Português como Segunda Língua para Comunidades de Trabalhadores Transplantados. Revista da SIPLE, v. 2, 2011.

BAERNINGER, Rosana Aparecida. O Brasil na rota das migrações internacionais recentes. Jornal da Unicamp, Campinas, Ed. 226, 25-31, 2003.

BUSCH, Brigitta. The Linguistic Repertoire Revisited. Applied Linguistics, 2012, p. 1-22.

CANAGARAJAH, Suresh. Language shift and the family: Questions from the Sri Lankan Tamil diaspora. Journal of Sociolinguistics, 12(2), 1-34, 2008.

CANAGARAJAH, Suresh. Translingual Practices - Global Englishes and Cosmopolitan Relations. New York: Routledge, 2013.

$\mathrm{CHO}$, U. Korean families on the forefront of globalization: A case study of new global mother-child families. Economics and Society [kyeongcey wa sahoy], 64, 148-173, 2005.

CHOI, Keun Joa. Além do arco-íris: a imigração coreana no Brasil. Dissertação (Mestrado), Programa de Pós-Graduação em História, USP, 1991. 
COELHO, Veronica. G. Casais Inter-étnicos - filhos Bilíngues? Representações como indícios de políticas de (não)transmissão da língua minoritária da família. Dissertação (Mestrado). Programa de Pós-graduação em Linguística Aplicada, UNICAMP, 2009.

FLICK, Uwe. Introdução à pesquisa qualitativa. $3^{\text {a }}$ Ed. Porto Alegre: Artmed, 2009.

FOGLE, Lyn. W.; KING, Kendall. A. Child agency and language policy in transnational families. Issues in Applied Linguistics, 19, 2013.

HALL, Stuart. The Work of Representation. In: S. Hall (org.) Representation: cultural representations and signifying practices. Londres: Thousand Oaks/New Deli: Sage/Open University, 1997, p. 2-73.

HELLER, Monica. Globalization, the new economy, and the commodification of language and identity. Journal of sociolinguistics, 7(4), 473-492, 2003.

HELLER, Monica. (Ed.) (2007). Bilingualism: A Social Approach. London: Palgrave Macmillan.

HORNBERGER, Nancy. Frameworks and models in language policy and planning. In: RICENTO, Thomas. (Ed.), An introduction to language policy: Theory and method, 2006, pp. 24-41.

JACQUEMET, Marco. Transidiomatic practices: Language and power in the age of globalization. Language \& Communication, 25(3), 257-277, 2005.

KAYAM, Orly; HIRSCH, Tyhana. Israel's English Speaking Immigrant Parents' Family Language Policy Management: Language in the Education Domain. International Journal of Linguistics, 5(1), 320, 2013.

KING, Kendall; FOGLE, Lyn.; LOGAN-TERRY, Aubrey. Family language policy. Language and Linguistics Compass, 2(5), 907-922, 2008.

KIM, Gwangjo. Education policies and reform in South Korea. Secondary education in Africa: Strategies for renewal, p. 29-39, 2002.

KIM, Kyounghee. Change and challenge of Korean family in the era of globalization: Centering transnational families. Journal of Ritsumeikan Social Sciences and Humanities 1: 167-87, 2009.

LEE, Hakyoon. 'I am a Kirogi mother': Education exodus and life transformation among Korean transnational women. Journal of Language, Identity and Education, 9(4), 250-264, 2010.

MAHER, Terezinha de Jesus Machado Maher. Ecos da Resistência: políticas linguísticas e as línguas minoritárias brasileiras. In: NICOLAIDES et alii (Orgs.) Política e Políticas Linguísticas. $1^{\circ}$ Ed.Campinas: Pontes Editores, 2013, v. 1, p. 117-134.

MARTIN-JONES, Marylin.; BLACKLEDGE, Adrian. e CREESE, Angela. Introduction: a sociolinguistics of multilingualism for our times. In: MARTIN-JONES, Marylin; BLACKLEDGE, Adrian. e CREESE, Angela. (Orgs.) The Routledge Handbook of Multilingualism. London: Routledge, 2012, p. 1-26.

MOITA LOPES, Luiz Paulo. Ideologia linguística: como construir discursivamente o português no século XXI. In: MOITA LOPES, L. P. (Org.) O Português no Século XXI: cenário geopolítico e sociolinguístico. São Paulo: Parábola, 2013, p. 18-52.

MORONI, Andrea. Português como Língua de Herança: o começo de um movimento. In: JENNINGS-WINTERLE, Felicia.; LIMA-HERNANDES, M. C. (Org.), Português como Língua de Herança: A filosofia do começo, meio e fim. Nova York: Brasil em Mente, 2015.

PARK, Sojin; ABELMANN, Nancy. Class and cosmopolitan striving: Mother's management of English education in South Korea. Anthropological Quarterly, 77(4), 645-672, 2004.

PARK, Sohyun, LIM, Hyunchul, e CHOI, Heekyung. (2015). Gangnam Mom: A Qualitative Study on the Information Behaviors of Korean Helicopter Mothers. Conference 2015 Proceedings. 
PILLER, Ingrid; $\mathrm{CHO}$, Jinhyun. Neoliberalism as language policy. Language in Society, 42(01), 23-44, 2013.

REYES, Angela. Linguistic Anthropology in 2013: Super-New-Big. In: American Anthropologist, vol. 116, No. 2, pp. 366-378, 2014.

RYMES, Betsy. Communicative repertoire. In: B. STREET; C. LEUNG (Eds.), Routledge companion to English language studies. New York, NY and London, England: Rouledge, 2014.

SHOHAMY, Elana. Language policy: Hidden agendas and new approaches. Psychology Press, 2006.

SPOLSKY, Bernard. Language policy. Cambridge University Press, 2004.

SPOLSKY, Bernard. Language management. Cambridge University Press, 2009.

SPOLSKY, Bernard. Family language policy-the critical domain. Journal of Multilingual and Multicultural Development 33.1: 3-11, 2012.

WOOLARD, Kathryn. A. Introduction: Language ideology as a field of inquiry. In: SCHIEFFELIN, Bambi; WOOLARD, Kathryn. A.; KROSKRITY, Paul. Language ideologies: Practice and theory, 1998. 